\title{
DESIGNING AND MANAGING MULTIPLE PIPELINES
}

by

\author{
James Aitken \\ Paul Childerhouse \\ University of Waikato \\ Martin Christopher \\ Cranfield University
}

and

\author{
Denis Towill \\ Cardiff University
}

The general tendency in the past has been for organizations to take a "supply-centric" view of supply chain design rather than a "customer-centric" perspective. It could be argued that conventional supply chains have been developed "from the factory outwards" rather than "from the customer backward." In other words, supply chain decisions have traditionally been made with the objective of maximizing the supplying company's efficiencies with the aim of providing an acceptable level of service at least cost. This approach is becoming less viable as customers move into the driving seat with increasing demands for a tailored logistic response (Fuller, O'Connor, and Rawlinson 1993).

To be successful in the challenging markets of the $21^{\text {st }}$ century, organizations need to develop the capabilities necessary to achieve a much higher level of customized response to the different needs of different customers. Indeed it seems that to be successful in these markets companies will need not just one supply chain solution but many. The implications of this transformation are significant: designing and managing multiple pipelines will become a necessary competence in the search for competitive advantage.

This paper builds partly on the earlier work of Hill (1993) who emphasized the importance of recognizing the Order Winners/Market Qualifiers (OW/MQ) in specific markets in order that appropriate operations strategies can be defined. Market Qualifiers are the "givens" that have to be embedded in the offer in order to be considered as a supplier. Order Winners are the critical elements that influence the final purchase decision. Our proposal is that once the Order Winners and Market 
Qualifiers are clearly understood, then appropriate supply chain solutions can be designed and implemented. It is also apparent that Order Winners and Market Qualifiers are dynamic. In other words they will change over time and hence what constitutes an appropriate supply chain strategy will also need to be revised over time (Christopher and Towill 2000a). The paper also recognizes the groundbreaking work of Fisher (1997) in alerting organizations to the need to match the design of their supply chains to product and market characteristics. Other influences included Naylor, Naim, and Berry (1999), who sought to marry the "lean" and "agile" supply chain paradigms to improve market responsiveness.

It is helpful to make a distinction between supply chains and pipelines. The supply chain is defined as the network of connected and interdependent organizations that work together to enable the flow of products into markets, whereas a "pipeline" is defined as the specific operational mechanisms and procedures that are employed to service specific product/market contexts. Thus within a single supply chain there could be a number of unique pipelines.

To support this viewpoint, a case study of a real world lighting company (LightCo) is presented. The company required four pipelines to adequately service its supply chain as it developed over a four-year time period. Both lean and agile operations were required in order to optimize customer service. The pipelines utilized varied according to the phase of the product life cycle so that items were switched and re-routed as their demand category changed. The challenge to the company - as indeed to all companies - was how to meet the needs of different market segments while managing a portfolio ranging from standard products with predictable demand to one-off customized solutions.

For designing and implementing such a multiplicity of pipelines, a product classification schema is proposed analogous to the system proposed by Christopher and Towill (2000b), and provides a mechanism for "clustering" products so that pipeline engineering judgements may be made. As Fuller, O'Connor, and Rawlinson (1993) state, some product consolidation is usually required; the classification system helps pinpoint where this is possible.

An important output from the present paper is a suggested generic family of delivery pipeline strategies. The seven discrete pipelines are termed pure standardization; compressed life cycle; compressed time-to-market; mass customization via assembly; logistics postponement; mass customization via processing; and pure customization. This categorization results from an analysis and synthesis of the pipelines and delivery strategies proposed by Childerhouse, Aitken, and Towill (2002), Lampel and Mintzberg (1996), Pagh and Cooper (1998), and Shewchuck (1998). It is suggested that identifying this generic family of delivery pipelines greatly eases technology transfer and the establishment of "best practice" because it becomes much clearer how pipeline performance may be measured and compared in a meaningful way. Additionally, recognizing differences between pipelines, new and more effective costing systems may be introduced, thus avoiding undesirable cost-averaging when fixing prices charged to individual customers (Fuller, O’Connor, and Rawlinson 1993). 


\section{LEAN, AGILE, AND LEAGILE}

Recently there has been considerable debate about the relative merits of "lean" and "agile" supply chains (e.g., Stratton and Warburton 2001). While these concepts are not necessarily mutually exclusive, they are different. Agility is a business-wide capability that embraces organizational structures, information systems, logistics processes and, in particular, mindsets. A key characteristic of an agile organization is flexibility. Indeed the origins of agility as a business concept lie in flexible manufacturing systems (FMS). Initially it was thought that the route to manufacturing flexibility was through automation in order to enable rapid change. Later it was realized that reducing set-up times, e.g., the Single-Minute-Exchange of Dies (SMED) concept provided a better way forward. This resulted in a greater responsiveness to changes in product mix or volume. The concept of manufacturing flexibility was extended into the wider business context (Nagel and Dove 1991) and the concept of agility as an organizational orientation was born.

By contrast the idea of "lean," as originally characterized in the Toyota Production System (TPS), is focused around the elimination or reduction of waste (muda) and the maximization of efficiency through level scheduling (Womack and Jones 1996). While leanness may be an element of agility in certain circumstances, by itself it will not enable the organization to meet the precise needs of the customer more rapidly. Webster's Dictionary makes the distinction clearly when it defines lean as "containing little fat" whereas agile is defined as "nimble." We need an interpretation of these definitions which translates into the supply chain scenario. A convenient interpretation of both paradigms is provided by Naylor, Naim, and Berry (1999) as follows:

Agility means using market knowledge and a virtual corporation to exploit profitable opportunities in a volatile marketplace.

Leanness means developing a value stream to eliminate all waste, including time, and to enable a level schedule.

In this paper, we want to emphasize that both lean and agile philosophies have important roles to play in enabling customized pipelines. Indeed, in the ideal world, supply chains would embody both lean and agile principles to ensure the highest level of market responsiveness combined with low cost and efficient processes. The particular value stream configuration in which upstream processes are lean and are then followed by downstream agile processes has been termed "leagile" (Naylor, Naim, and Berry 1999). So by having some upstream lean processes we enable a low cost and a low risk supply chain while simultaneously achieving downstream agility and high levels of customer responsiveness. Adopting the Leagile Paradigm fits well alongside the seminal idea of postponement, advocated by Bowersox and Closs (1996) and Feitzinger and Lee (1997) among others. 


\section{THE IMPACT OF "ORDER WINNERS" AND "MARKET QUALIFIERS"}

The work of Hill (1993) has alerted managers to the idea that there are certain things that companies must do well to even be considered as potential suppliers. These competitive pre-requisites can be termed "market qualifiers." However, these elements represent the base level of performance. In order to succeed in that market the company must out-perform the "order winners." In other words, these are the critical differentiators.

In practice, there will often be a relatively small number of performance criteria which constitute market qualifiers and order winners e.g., price, quality, delivery lead time, and reliability.

Figure 1 suggests that, depending upon the relative importance attached by potential customers to these criteria, different supply chain strategies may be required. Thus, where responsiveness is a key requirement demanding short lead-times, the focus is clearly on agility. In this case, quality and reliability could be the market qualifiers. At the other extreme, if price is the order winner, then the emphasis must be on low cost supply chain solutions (i.e., lean) again with quality and reliability could be the market qualifiers.

\section{FIGURE 1}

\section{ORDER WINNERS AND MARKET QUALIFIERS AS DETERMINANTS OF SUPPLY CHAIN FOCUS}

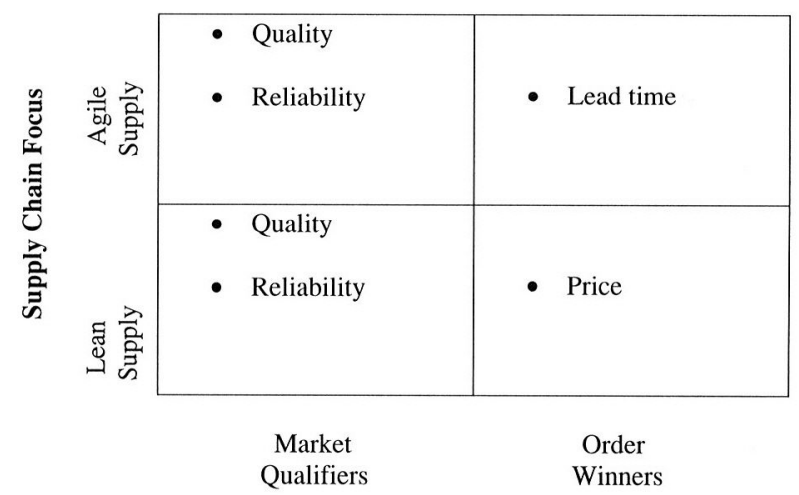

Market Requirements

(Source: Based on Mason-Jones, Naylor, and Towill 2000) 
Given that the reality today is that increasingly customers demand both responsiveness and low price, the challenge is to identify supply chain strategies which bring lean and agile thinking together, i.e., so-called "leagile" solutions.

\section{THE SUPPLY CHAIN MIGRATORY MODEL}

An important idea arising from the work of Johansson et al. (1993) is that the properties of order winners/market qualifiers are cyclical in nature. Hence this year's winner regresses to next year's qualifier as the opposition play "catch-up." This is demonstrated in the Supply Chain Migratory Model proposed by Christopher and Towill (2000b) and summarized in Table 1. As suggested by Schonberger (1996), "annual stock turns" has been added to this table as an important business performance metric. This measures the risk to the business of excessive and usually expensive inventory becoming obsolescent, a key factor in supplying short life cycle products and an issue of increasing importance in present day value streams. The model shows that in the early 1980 's the order winner was quality, which for Western industry was needed to combat Japanese imports, and was achieved within the lean internal process scenario. This was followed by the implementation of the lean supply chain impacting on cost, but still "pushing" products into the marketplace in the sense of not responding to specific needs.

Then came the era enabled by the use of the material flow de-coupling point in the particular hybrid lean-agile supply chain termed "leagile" by Naylor, Naim, and Berry (1999). This chain is agile enough to respond to what is actually selling with availability as order winner. Finally, as instanced by present-day Dell Computers (Dell and Freedman 1999), we have the customized leagile supply chain. Thus by further streamlining the supply chain front end, Dell aims to supply exactly what the individual customer selects. Lead time is now the order winner with a maximum of seven days allowed for pulling off the requisite sub-assemblies, finalizing the PC, adding the exact peripherals, packaging, and delivery to the individual customer. 
TABLE 1

\section{MIGRATORY MODEL SUMMARIZING THE TRANSITION FROM LEAN FUNCTIONAL SILOS TO CUSTOMIZED LEAGILE SUPPLY CHAIN}

\begin{tabular}{|c|c|c|c|c|}
\hline $\begin{array}{l}\text { Supply Chain } \\
\text { Evolution Stage }\end{array}$ & I & II & III & IV \\
\hline $\begin{array}{l}\text { Supply Chain } \\
\text { Time Marker }\end{array}$ & Early 1980 s & Late 1980 s & Early 1990 s & Late $1990 \mathrm{~s}$ \\
\hline $\begin{array}{l}\text { Supply Chain } \\
\text { Philosophy }\end{array}$ & Product Driven & Volume Driven & Market Driven & Customer Driven \\
\hline SC Type & $\begin{array}{l}\text { Lean Functional } \\
\text { Silos }\end{array}$ & $\begin{array}{l}\text { Lean Supply } \\
\text { Chain }\end{array}$ & $\begin{array}{l}\text { Leagile Supply } \\
\text { Chainn }\end{array}$ & $\begin{array}{l}\text { Customized Leagile } \\
\text { Supply Chain }\end{array}$ \\
\hline Order Winner & Quality & Cost & Availability & Lead Time \\
\hline Market Qualifiers & $\begin{array}{l}\text { (a) Cost } \\
\text { (b) Availability } \\
\text { (c) Lead Time }\end{array}$ & $\begin{array}{l}\text { (a) Availability } \\
\text { (b) Lead Time } \\
\text { (c) Quality }\end{array}$ & $\begin{array}{l}\text { (a) Lead Time } \\
\text { (b) Quality } \\
\text { (c) Cost }\end{array}$ & $\begin{array}{l}\text { (a) Quality } \\
\text { (b) Cost } \\
\text { (c) Availability }\end{array}$ \\
\hline Performance Metrics & $\begin{array}{l}\text { (a) Stock Turns } \\
\text { (b) Production Cost }\end{array}$ & $\begin{array}{l}\text { (a) Throughput Time } \\
\text { (b) Physical Cost }\end{array}$ & $\begin{array}{l}\text { (a) Market Share } \\
\text { (b) Total Cost }\end{array}$ & $\begin{array}{l}\text { (a) Customer } \\
\text { Satisfaction } \\
\text { (b) Value Added }\end{array}$ \\
\hline
\end{tabular}

(Source: Christopher and Towill 2000b)

Our evolutionary model of supply chain migration can be interpreted as the move from traditional (product driven) through lean (volume driven) via leagile (market driven) to customized leagile (individual customer driven) operation. These stages in supply chain evolution are best visualized by understanding how goods arrive at the marketplace. "Product driven" means "sell what we are able to make," whereas "volume driven" means "maximize market share". In this sense, "Leagile" is responsive to true market demand, but only from a finite catalog of standard products. Because in this mode of operation availability is the order winner, fast-selling goods need to be manufactured and supplied quickly to replenish retailer's shelves. Furthermore, a supply chain usually maximizes profitability by managing a bundle of value streams. Each is matched to a particular and very demanding marketplace need. So it is possible, as we shall demonstrate, to encounter lean, agile, and leagile value streams forming independent pipelines within a given supply chain (Childerhouse, Aitken, and Towill 2002). Naturally the "order winners" will vary according to the particular pipeline utilized for that product.

\section{THE AVAILABILITY FULCRUM}

At its simplest the purpose of any supply chain is to balance supply and demand. Traditionally this has been achieved through forecasting ahead of demand and creating inventory against that fore- 
cast. Alternatively additional capacity might be maintained to cope if demand turned out to be greater than forecast. Either way in an ideal world demand is balanced with supply. Figure 2(a) shows a typical balanced supply chain. Now imagine that by some means or other, yet to be discussed, the fulcrum is moved closer to the demand box as in Figure 2(b). Obviously the same amount of demand can now be balanced with less inventory and/or less capacity. Clearly for many business scenarios this will be highly advantageous, but it manifestly requires both product and value stream to be appropriately engineered to achieve this objective.

What does the fulcrum actually represent in a supply chain? The fulcrum is the point at which we commit to source/produce/ship the product in its final form and where decisions on volume and mix are made. The idea here is that if that point of commitment can be delayed as long as possible then the closer we are to make-to-order, i.e., mass customization, with all the consequential benefits this brings. In practice the problem for many companies is that the fulcrum in their supply chains is more like that shown in Figure 2(c). Here the fulcrum is a long way from demand i.e., the forecasting horizon is long, necessitating more inventory and capacity to balance against demand. So it is clear that responding to the volatility of present-day customer demand requires the availability fulcrum to be located closer to demand.

\section{FIGURE 2}

\section{THE SUPPLY CHAIN AVAILABILITY FULCRUM}

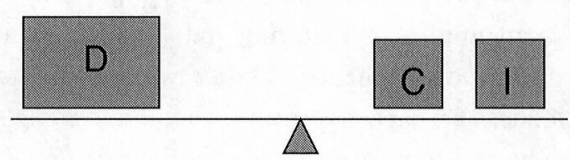

(a) The typical supply chain inventory/capacity needed to balance demand.

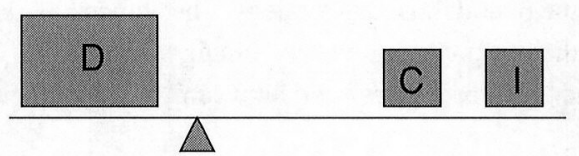

(b) Fulcrum moved nearer to demand, hence smaller inventory/capacity is required.

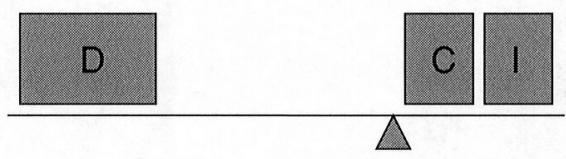

(c) Fulcrum moved too far from demand, hence larger inventory/capacity is required. 
How in reality do we achieve this goal? The answer is to improve visibility of demand along with enhancing the velocity of the supply chain. In other words, if we can have a clearer view of real demand in the final marketplace, rather than the distorted picture which more typically is the case, and if we can respond more rapidly then a more effective matching of supply and demand can be achieved. Thus it can be argued that visibility and velocity are the foundations for a customized supply chain. A related idea is that of the "information de-coupling point" (Mason-Jones and Towill 1999). Effectively this notion suggests that the further upstream information on real demand can flow then the more responsive the supply chain as a whole becomes.

While is has long been recognized that a key goal in any logistics system should be to "substitute information for inventory," the real challenge is to achieve this through greater levels of information sharing between supply chain partners. This in turn requires closer and more trusting relationships between the different entities in the supply chain.

\section{THE ROLE OF POSTPONEMENT}

The concept of "postponement" is well established in logistics and supply chain management. Postponement can be physical, spatial, or temporal (Christopher 1998). In other words, we can delay the final configuration, assembly, or packaging of the product (physical postponement); the geographical dispersal of the product (spatial postponement); or the time at which we commit to a decision (temporal postponement).

Figure 3 depicts the postponement matrix proposed by Pagh and Cooper (1998). This differentiates between the postponement of manufacturing and the postponement of logistics activities as different options for the movement of the availability fulcrum of Figure 2 toward the point of demand. Such a movement reduces the capacity/inventory required to cope with volatility in the marketplace and also enables product customization by not configuring until firm orders are known. We have populated Figure 3 with a number of real-world industrial examples. Our selection is based on a desire to show that each cell of the postponement matrix is a viable candidate pipeline to be selected as appropriate to the overall business strategy. The choice has also reflected the wide market sector applicability of the postponement matrix. Finally, we note that there is broad equivalence between "speculation" and "lean processes" and between "postponement" and "agile processes." 


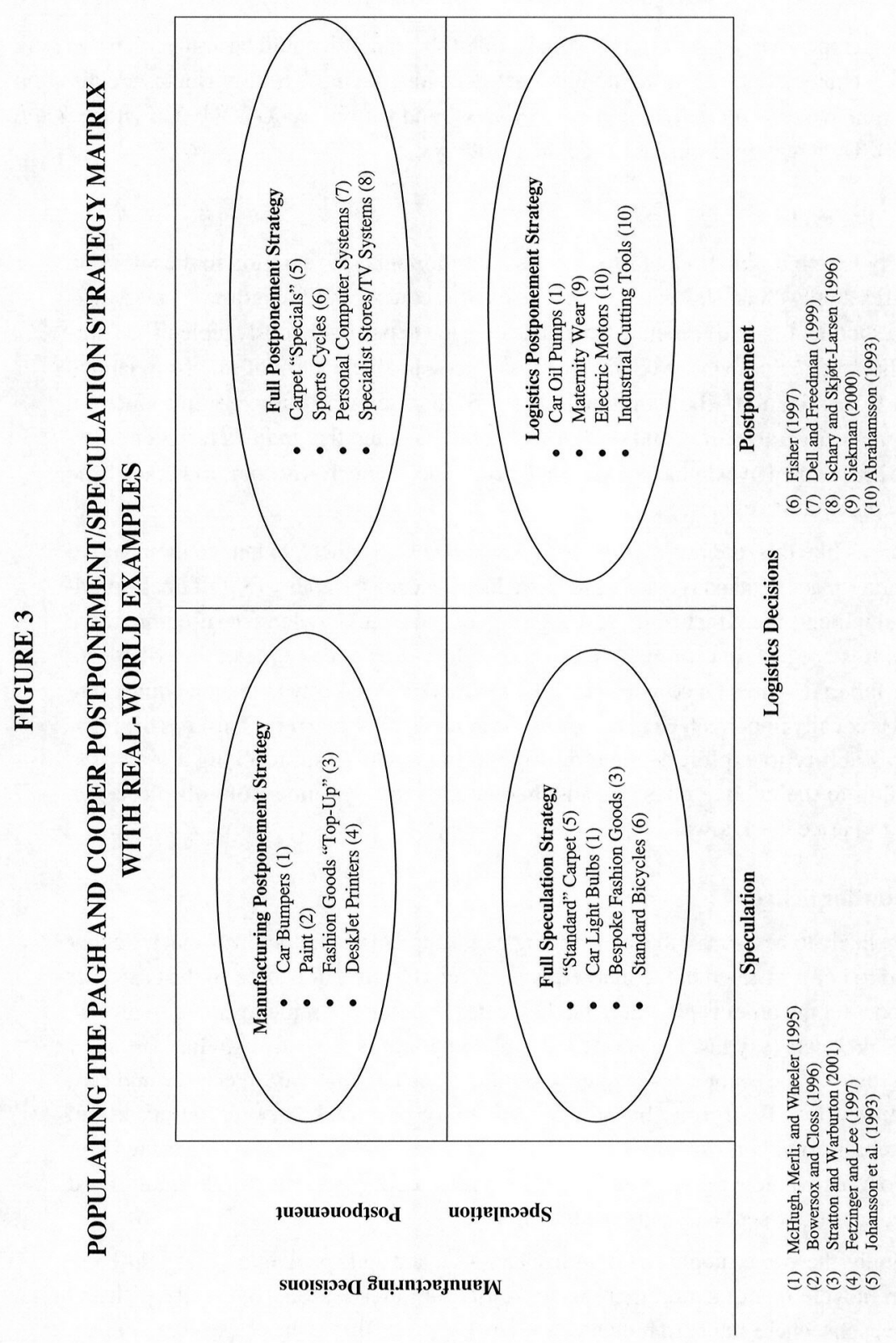

Reproduced with permission of the copyright owner. Further reproduction prohibited without permission. 


\section{MARKET CHARACTERISTICS}

From the perspective of the design of supply chain strategies, it could be argued that there are five key market characteristics that should influence decision making. These attributes are duration of life cycle; time window for delivery; volume; variety; and ariability (DWV ${ }^{3}$ ) (Christopher and Towill 2000b). They may be described in detail as follows:

\section{- Duration of life cycle}

The likely length of the product life cycle is an important consideration in the adoption of specific supply chain strategies. Short life cycles require both rapid time-to-market as well as a short end-to-end "pipeline" to enable demand to be continuously replenished during the life cycle. For many products there is a recognizable pattern of sale from launch through to termination. The individual phases of the life cycle curve are introduction, growth, maturity, saturation, and decline. It should be noted that today's turbulent marketplace has resulted in extreme volatility and hence uncertainty has become a characteristic of many product life cycles.

In situations like this, the time available to develop new products, to launch them and to meet market-place demand is clearly greatly reduced. Hence the ability to "fast track" product development, manufacturing, and logistics becomes a key element of competitive strategy. It is not just time-to-market resulting in lost sales that is a major contributor to the shortfall in revenue. Once a product is on the market the ability to respond quickly to demand is equally important. Here the lead-time to re-supply a market determines the organization's ability to exploit demand during the life cycle. Also, too long a lead-time responding to the decline phase means that we also lose revenue from obsolescence resulting in price markdowns.

\section{- Time window for delivery}

It is more likely to be the case that agile strategies are appropriate for products that are either expected to be short-lived in the marketplace, or require to be delivered to the customer very soon after the order is placed. In the first category, we need rapid response to replenish those products (say fashion goods and mobile phones) selling well at that particular point in time. In the second case we have products such as customized carpets and customized bicycles. The former has a time window of one week between purchase and subsequent fitting in the customer's residence (Johansson et al. 1993) whereas the latter has a two week window between customer being measured up/selecting cycle features and local delivery (Lowson, King, and Hunter 1999).

Interestingly, these two supply chains utilize both lean and agile paradigms, but in different ways. In bicycle manufacture, there is an "agile" summer season, followed by "lean" winter seasons where standard models are made for stock. But in the carpet supply chain 
there are two parallel value streams operating continuously and concurrently. The first produces customized "agile" products, whereas the second manufactures the standard "lean" carpet ranges, which are made for stock.

\section{- Volume}

Where products are aimed at mass markets with a prospect of a high level of demand, conditions will often allow lean-type production and make-to-forecast strategies to be designed and implemented. Thus the focus can be on maximizing the economies of scale. Conversely, where volumes are likely to be smaller the benefits of flexibility, both in production and the wider supply chain, will be evident. However, it is important to recognize the impact of the Pareto distribution (the $80 / 20$ rule). In other words at a particular point in time the top $20 \%$ of the range may sell in substantial volume but the remaining $80 \%$ will be much slower moving. Hence it will sometimes be appropriate to adopt lean strategies for the top $20 \%$ and agile strategies for the remaining $80 \%$ where we do not want to over-stock or overproduce. But the Pareto Curve is itself dynamic as the volumes vary through out the product life cycle. Hence today's "runner" may be tomorrow's "repeater" and next week's "strangers" (Parnaby 1994). We therefore need a supply strategy to cope with such changes in emphasis during the product lifecycle.

\section{- Variety}

Typically, the higher the level of variety demanded by the marketplace, the lower will be the average volume per variant because total demand is spread across a greater number of stock keeping units (SKUs). This will often mean that demand will be more variable at the SKU level. It also implies a much higher level of flexibility in manufacturing with a need for more change-overs and set-ups. With increased variety generally comes greater complexity. The challenge is to seek to achieve a higher level of commonality at the Bill of Material level but to enable late configuration or customized finishing to meet the customer demand for variety.

\section{- Variability}

The concept of variability relates to the "spikiness" of demand. It also equates to unpredictability. Where demand cannot be forecast with any degree of accuracy, it is suggested that agility is critical. A measure of variability is the Coefficient of Variation (standard deviation divided by the mean). Where the coefficient of variation is high, then reliance on forecast-based management is to be avoided. Instead the focus must be upon lead-time reduction and the substitution of information for inventory. In other words, capturing information on demand as close to the marketplace as possible. This means that the "information enriched" operation is a key enabler in agile supply (Mason-Jones and Towill 1997). Quick response is then activated by true demands, rather than rogue demands. 
Using the DWV ${ }^{3}$ framework to analyze a company's product portfolio will highlight the need for different pipelines to cater for the diversity of product/market profiles. Even if each of these five dimensions were at their simplest only bi-polar then this would still imply 32 (i.e., $2^{5}$ ) pipelines. However, as the following case study suggests, in reality fewer pipelines will be required through clustering products into generic families.

\section{THE LIGHTCO CASE STUDY}

To illustrate the opportunities that exist for managing multiple pipelines to enable tailored logistics solutions, the case of LightCo is presented. LightCo is a company producing a range of lighting products for diverse markets. Their product range varies from standard products made in volume (e.g., white fluorescent tubes) to architect-specified systems for large one-off projects (e.g., airport terminals).

Before 1996, the LightCo's organization and management of its internal and external demand chains was based on a traditional functional approach. All seven forms of Ohno's (1988) wastes (or muda) were very apparent in the internal demand chain and material conversion operations. Management of the external supply chain was at an arm's-length contractual basis (Sako 1992). No obligation for repeat transactions was anticipated if the supplier did not maintain the lowest price. To overcome these problems, the company embarked on a two-phase, four year re-engineering program (Aitken 2000). The first phase resulted in the introduction of lean production, while the second phase was aimed at making the plant responsive. But the clear aim of the re-engineering program was to match customer requirements and product delivery processes. Using the DWV ${ }^{3}$ supply chain classification described earlier enabled the segmentation of the product catalog into a smaller number of focussed clusters. The next step was to design and engineer the four pipelines, which are summarized in Figure 4. This was deemed the optimum number of pipelines in the trade-off between economies of scale, economies of scope, and diseconomies of averaging.

Cluster 1 consists of the low volume products. This cluster is akin to the concept of "strangers" in Lucas terminology (Parnaby 1994) i.e., products for which demand is sporadic. It was decided that the existing MRP control mechanisms were the most appropriate for these types of products. The major order winner for this cluster of products is service level in terms of availability of small volume products within acceptable lead times. Cluster 2 , the high volume, low variant products are increasingly becoming commodity-like in nature and are exposed to competition from low labor cost countries. Since the UK lighting company cannot win on the basis of cost alone, very short lead times are the only remaining competitive avenue. This is facilitated via a lean supply channel and a maketo-stock policy, so that deliveries to specific customer orders can be made in very short lead times ( 1 day if required). The Kanban controls and 2-bin system operated with the supply base maximizes efficiency for these products with relatively predictable demand patterns. 


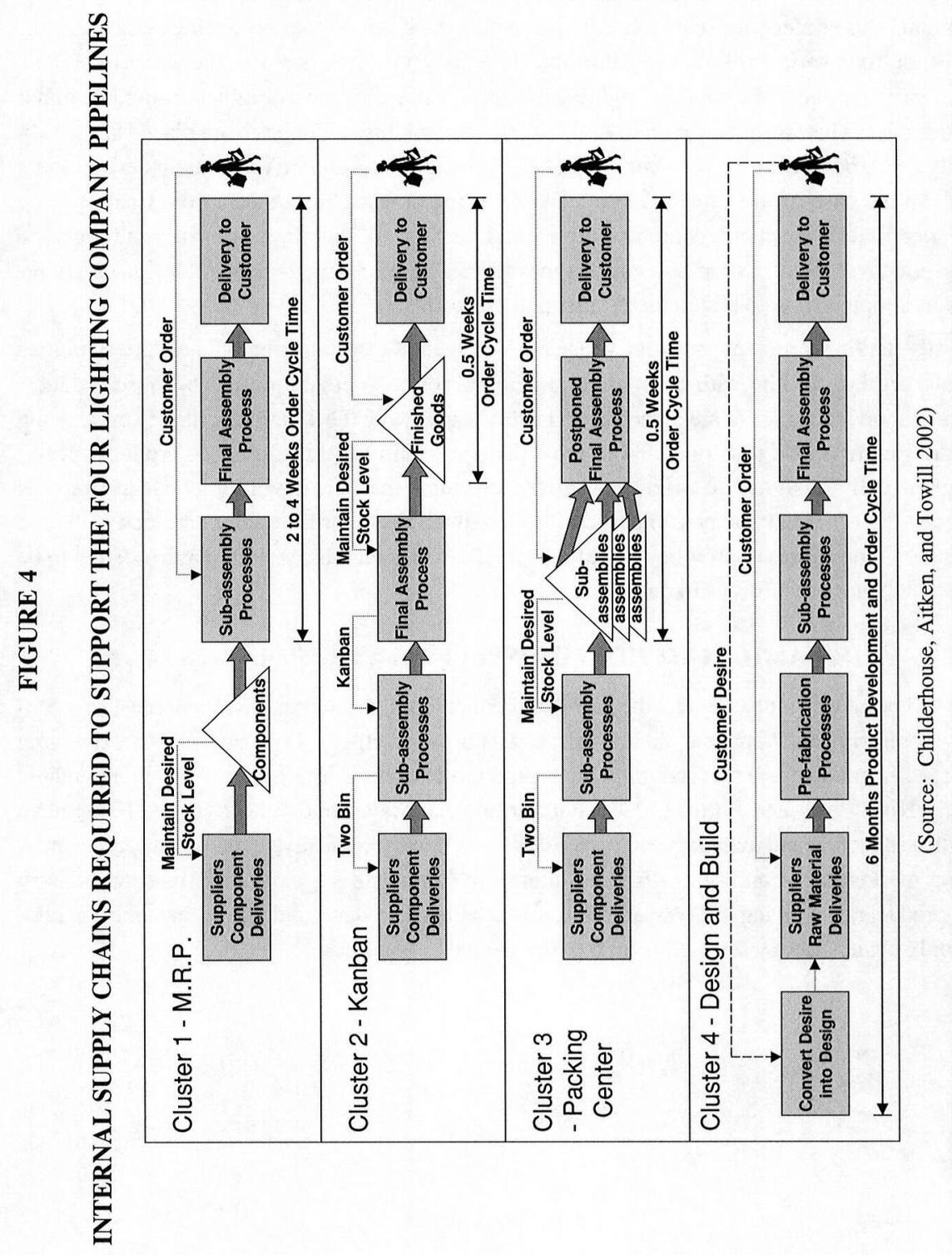


To further combat overseas competition the lighting company and its associated supply chain increased customer service by offering multiple variants of relatively standard products. The products utilizing this strategy make up Cluster 3 for which the order winner is cost followed by availability of multiple variants. To achieve this objective, the concept of postponement was exploited. This was partially due to the nature of lighting products in that they are assembled from three major sub-assemblies. Therefore, as shown in Figure 4, the de-coupling point has been placed at the subassembly level. Before the de-coupling point, Lean principles are applied to maintain desired stock levels as in the case of the Cluster 2 products. After the de-coupling point, in the final packing center, specific customer orders are assembled and dispatched, therefore offering multiple variants cost effectively in very short order cycle times. Thus a Leagile strategy (Naylor, Naim, and Berry 1999) was adopted so as to obtain the best from both worlds.

Lastly the final group of products, Cluster 4 , was seen as offering potential new opportunities in the marketplace in line with the increased demand for customized products. These products either have short life cycles or are in their introductory stages, with the duration of the life cycle being uncertain. Figure 4 also illustrates the internal demand chain for this cluster of products. It has been specifically designed to offer customized products in short development lead times as effectively and efficiently as possible, therefore maximizing the order winning objective. These re-engineering programs to provide customized pipelines also enabled activity based costing to be used to match price to effort (Aitken 2000).

\section{DYNAMIC MATCHING OF PIPELINES AND PRODUCTS}

At this point we emphasize that the LightCo product routing is not static so there must be a continuous monitoring and appraisal of all SKUs. In fact the marketplace OWs and MQs are dynamic for any specific product as it proceeds through its product life cycle. This is noted by numerous authors including Hill (1993) and Porter (1980). Furthermore, as Hayes and Wheelwright (1984) have stated, the production and manufacturing processes must also dynamically adapt to best service these changing marketplace conditions. Figure 5 therefore summarizes a particular lighting industry generic product range giving its OWs and MQs for each life cycle stage, and the resultant most applicable supply chain strategy selected from the four available pipelines. 


\section{FIGURE 5}

\section{HOW OW AND MQ CHARACTERISTICS CHANGE AS A FUNCTION OF LIFE CYCLE}

(Source: Childerhouse, Aitken, and Towill 2002)

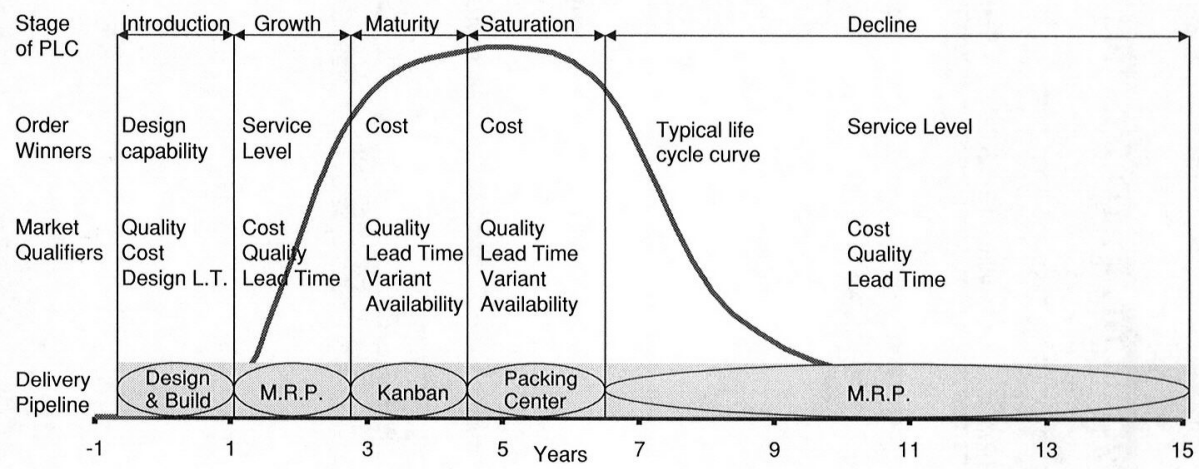

During the introduction stage of the product life cycle, the capability of design is the key OW followed closely by the design lead time. Therefore the design and build strategy is most applicable. Once the product has entered the marketplace and if the demand increases, then the product enters its growth stage. During this time the service level in terms of availability of a product with unpredictable demand is the key OW. As a result the product is transferred to the MRP push based demand chain. When the product has reached its mature stage, it is switched to the Kanban demand chain so as to best compete on the key OW of cost. During the saturation stage, low labor cost countries enter and compete in the marketplace so LightCo competes by offering multiple variants. In order to do so, the packing center strategy is utilized. Finally, as the demand for the product tails off and enters the decline stage of the product life cycle, it is transferred back to the MRP pipeline so as to maximize the service level for the low volume highly unpredictable product.

This case is an excellent example of how a real-world manufacturer in an unglamorous market sector responds to the challenge outlined by Shewchuck (1998) to move away from the "one size fits all" mentality. Nor is LightCo operating in an industry where designing, implementing, and matching the optimum pipeline to product would be regarded as an obvious way to proceed. This is in contrast to the fashion and personal computer market sectors which tend to advertise their innovations in logistics and delivery policies quite widely. Furthermore as reported elsewhere (Childerhouse, Aitken, and Towill 2002) these moves into planned pipeline multiplicity have proven to be essential in order to sustain competitive advantage. The consequence is an impressive contribution to bottom-line performance (Aitken 2000). 


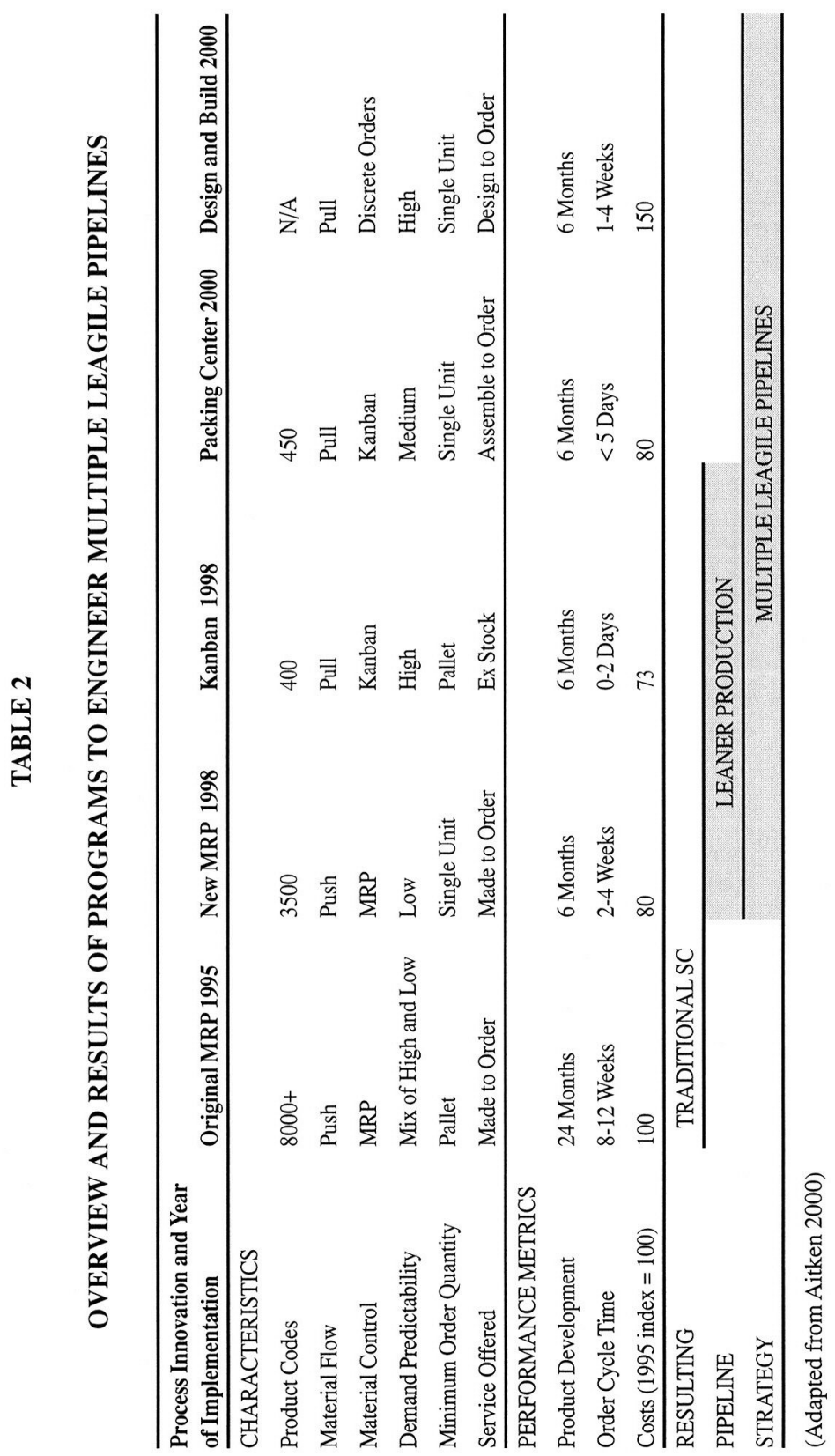




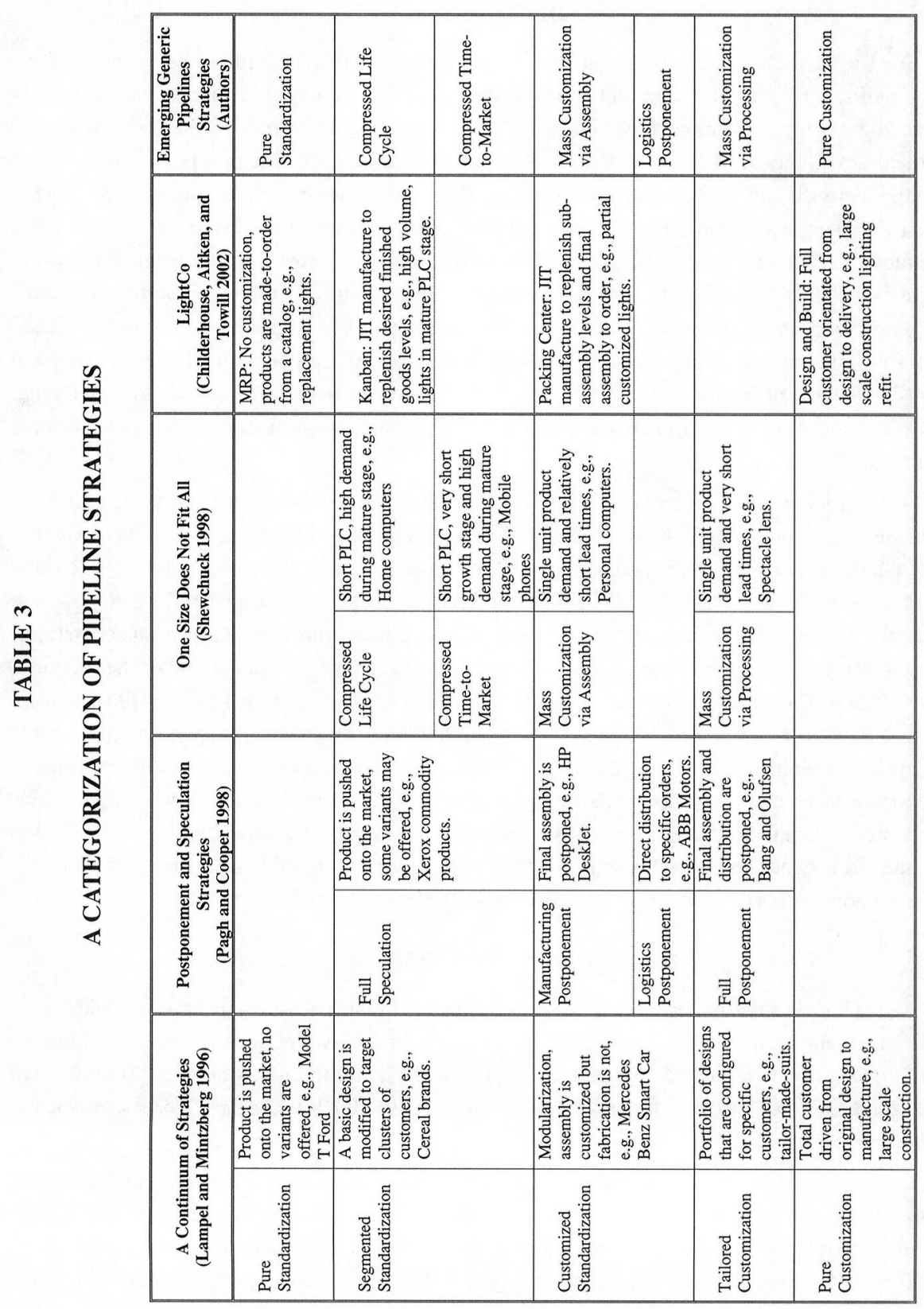




\section{DISCUSSION}

The LightCo case study offers a great deal of insight into the feasibility of developing a multiple pipeline strategy. The resultant four focused pipelines depicted in Figure 4 have greatly enhanced the competitiveness of the company and its supply chain partners. Table 2 illustrates the historical development of the four strategies, together with some of the observed benefits from using the focussed approach. Costs have been greatly reduced for three of the four channels. In the case of the Design and Build pipeline the apparent price increase is because re-engineering has facilitated identification of the true activity based costs. Thus the cross-subsidy from commoditylike products at the expense of other items, which is one of Fuller, O'Connor, and Rawlinson's (1993) important averaging effects, is avoided. The order cycle times have been massively reduced for all four pipelines but especially for the Kanban and Packing Center channels which often win orders on the basis of their responsiveness. Similarly the competitiveness of the customized Design and Build products has been greatly enhanced via the compression of the product development lead times.

One particular challenge that is highlighted by the LightCo case study is the issue of how companies can remain competitive in changing market conditions. Clearly the "one-size-does-notfit-all" philosophy is now an essential part of pipeline design and companies must build this into Business Process Re-engineering (BPR) Program requirements. In the case of LightCo the BPR "product champion," in this instance the CEO initially moved the company from traditional to lean operations. This step was helpful but inadequate to retain competitive advantage at either end of the spectrum (Aitken 2000). The current solution required the company to create four distinct pipelines. Consequently LightCo became more competitive in the high volume business by responding to overseas competition by offering a wider range of product variants. The Packaging Center facility has enabled customization and rapid response of particular products by moving the availability fulcrum of Figure 2 nearer to the marketplace via postponed manufacture. Finally, the re-positioning of the Design and Build facility has considerably improved responsiveness to the need to develop new products, which are now properly costed and not cross-subsidized by the fast movers.

\section{GENERIC PIPELINE STRATEGIES}

We are now in a position to embed the outputs from the LightCo Case Study into a generic framework. This is shown in Table 3 in which the four LightCo delivery pipelines are placed in the context of three earlier established approaches. These are the "continuum of strategies" (Lampel and Mintzberg 1996), the "one size does not fit all" strategy (Shewchuck 1998), and "postponement and speculation strategies" (Pagh and Cooper 1998).

An examination reveals that the broadest picture is painted by Lampel and Mintzberg (1996). They suggest that five delivery strategies are possible, described as pure standardization, segmented standardization, customized standardization, tailored customization, and pure customization. The postponement and speculation strategies of Pagh and Cooper (1998) can now be seen 
as intensive exploitation of the middle three categories. "Full speculation" therefore equates to "segmented standardization," while "full postponement" equates to "tailored customization." Interestingly, "customized standardization" is subdivided into "manufacturing postponement" and "logistics postponement" by Pagh and Cooper (1998). There are direct equivalences between Shewchuck's (1998) "mass customization via processing" with "tailored customization" and "mass customization via assembly" with "customized standardization." However both "compressed life cycle" and "compressed time to market" can be viewed as alternative adaptations of "segmented standardization."

The four LightCo pipelines fit well into this continuum of strategies. The "MRP pipeline" qualifies under "pure standardization," "Kanban" equates to "segmented standardization" the "packing center" with "customized standardization" and "design and build" with "pure customization." What does this mean? Firstly that there is agreement and consistency between the approaches by Pagh and Cooper (1998) and Shewchuck (1998) and the continuum of strategies defined by Lampel and Mintzberg (1996). But more importantly, it all relates to real-world practice as evidenced by the LightCo case. Furthermore LightCo have demonstrated the necessity for companies to establish parallel pipelines which may require quite different core skills to match the need for defined delivery categories. "Design and Build," for example, does not sit happily within an "MRP" environment.

Building upon the three previously cited contributions of Lampel and Mintzberg, Pagh and Cooper, and Shewchuck and the findings of the LightCo case, seven generic strategies emerge. These are highlighted in the right hand column of Table 3.

It is quite possible that within a large multi-product, multi-market company there will be a need to develop structures and capabilities to manage all seven pipelines. In other situations the requirement may be for fewer. However, the key message is that businesses must recognize the need to fit the appropriate pipeline to the specific characteristics of the product/market context. The challenge to any multi-product, multi-market business is clearly how best to manage multiple pipelines. It will not normally be feasible for organizations to contemplate designing, building, and operating up to seven distinct pipelines. However, many companies are now recognizing that if they standardize key business sub-processes across their supply chain network they can assemble those standard subprocesses in different ways to match the context in which they must operate. This is the way that Nokia, for instance, are able to customize their global supply chains (Korhonen, Huttunen, and Eloranta 1998).

It must also be recognized that there will be occasions when customers will order a mix of products from the company's portfolio and that mix might include products which fall into different categories as we have defined them. How will the supplying organization manage the consolidated delivery of such diverse customer orders where the individual order lines may now flow from different pipelines?

There is a very good parallel here with the idea of merge-in-transit (Kärkkäinen, Ala-Risku, and Holmstöm 2003). In the merge-in-transit environment products may originate from a variety of sources but are consolidated at an intermediate point for delivery to customers. Often this merge- 
in-transit will be managed by a Logistics Service Provider (LSP) but equally could be performed in-house.

\section{CONCLUSIONS}

Today's diverse marketplace presents a challenge to supply chain management in that different solutions are required for a range of customer requirements. When seen in such a context it is apparent that there is a portfolio of production technologies, product modularization techniques, logistics, postponement, and marketing ploys, which may be utilized to gain competitive advantage. Working from such a "pick and mix" scenario it then becomes much easier to select and implement multiple pipelines to serve all customers as the marketplace requires. As the "One Size Does Not Fit All" maxim (Shewchuck 1998) implies, this does not mean offering each customer the same: it means tailoring delivery to suit clusters of products and their marketplace needs. Thus the National Bicycle Company (Lowson, King, and Hunter 1999) has two clusters of products essentially manufactured by the same group of employees. But one cluster is a group of standard SKUs made to stock utilizing lean production. The second cluster offers personalized items necessitating agile responses for information elicitation, assembly, and rapid delivery to the customer. Steps must be taken to ensure that there is no "interference" between these channels, an objective achieved here via temporal separation (Christopher and Towill 2002).

The selection of the optimal set of pipelines appropriate to any particular business strategy should be preceded by careful in-depth analysis of products, production processes, and market opportunities. As our LightCo case study demonstrates, this is not an exercise to be undertaken lightly. In that instance, the outcome was the setting up of four parallel pipelines customized to the needs of particular clusters of products in such a way as to meet the specific Order Winners and Market Qualifiers appropriate to that group. In each pipeline, the availability fulcrum was moved to the appropriate position to balance demand with capacity/inventory requirements. In the case of one particular pipeline, final assembly was postponed but with rapid pull-off to enable quick response to customer orders. The outcome of this particular multiple pipeline strategy was a substantial positive impact on bottom-line performance.

Our analysis of the literature and the findings of the LightCo case study suggest a spectrum of generic pipeline strategies ranging from "pure standardization" to "pure customization."

In total, we have identified seven viable pipeline strategies and the likelihood is that in any company there will be a need, at some time, to utilize more than one of them. Managing multiple pipelines is already a reality for many companies, but in others the same facilities, principles, and rules are used no matter what the product/market context. Clearly, however, further empirical research is required to examine just how generic these suggested pipeline strategies might be. Also, too, the question needs to be raised as to the particular managerial skills, organizational formats, performance metrics, and corporate resources that are required to operationalize these different pipeline strategies. 
We began this paper with the assumption that supply chains should be "customer-centric." To enable this transformation to be achieved a deeper understanding of the interplay of product/market characteristics and customer requirements is required and that understanding has to be the driver that underpins the choice of pipelines within a supply chain.

\section{NOTES}

Abrahamsson, Mats (1993), "Time-Based Distribution," International Journal of Logistics Management, Vol. 4, No. 2, pp. 75-83.

Aitken, James (2000), "Agility and Leanness - A Successful and Complimentary Partnership in the Lighting Industry," in Proceedings of the LRN 2000 Conference: Cardiff University, pp. 1-7.

Bowersox, Donald J. and David J. Closs (1996), Logistical Management, New York: McGraw-Hill.

Childerhouse, Paul, James Aitken, and Denis Towill (2002), "Analysis and Design of Focussed Demand Chains," Journal of Operations Management, Vol. 20, No. 6, pp. 675-689.

Christopher, Martin (1998), Logistics and Supply Chain Management, London: Prentice Hall.

Christopher, Martin and Denis Towill (2000a), "Supply Chain Migration from Lean and Functional to Agile and Customized," International Journal of Supply Chain Management, Vol. 5, No. 4, pp. 206-213.

Christopher, Martin and Denis Towill (2000b), "Marrying the Lean and Agile Paradigms," in Proceedings of the EUROMA 2000 Conference: Ghent, pp. 114-121.

Christopher, Martin and Denis Towill (2002), "Developing Market Specific Supply Chain Strategies," International Journal of Logistics Management, Vol. 13, No. 1, pp. 1-14.

Dell, Michael and Catherine Freedman (1999), Direct from Dell: Strategies that Revolutionized an Industry, London: Harper Collins.

Feitzinger, Edward and Hau Lee (1997), "Mass Customization at Hewlett Packard - The Power of Postponement," Harvard Business Review, Vol. 75, No. 1, pp. 116-121.

Fisher, Marshall (1997), "What is the Right Supply Chain for your Product?" Harvard Business Review, Vol. 75, No. 2, pp. 105-116. 
Fuller, Joseph B, James O'Connor and Richard Rawlinson (1993), "Tailored Logistics: the Next Advantage," Harvard Business Review, Vol. 71, No. 3, pp. 87-98.

Hayes, Robert and Steven Wainright (1984), Restoring our Competitive Edge: Competing through Manufacturing, New York: John Wiley.

Hill, Terry (1993), Manufacturing Strategy: Text and Cases, $2^{\text {nd }}$ Ed. London: MacMillan Press.

Johansson, Henry, Patrick McHugh, John Pendlebury, and William Wheeler (1993), Business Process Re-Engineering, New York: John Wiley and Sons.

Kärkkäinen, Mikko, Timo Ala-Risku, and Jan Holmström (2003), "Increasing Customer Value and Decreasing Distribution Costs with Merge-in-Transit," International Journal of Physical Distribution and Logistics Management, Vol. 33, No. 2, pp. 132-148.

Korhonen, Pertti, Kati Huttunen, and Eero Eloranta (1998), "Demand Chain Management in a Global Enterprise - Information Management View," Production Planning and Control, Vol. 9, No. 6, pp. 526-531.

Lampel, Joseph and Henry Mintzberg (1996), "Customizing Customization," Sloan Management Review, Vol. 38, No. 1, pp. 21-30.

Lowson Robert, Russell King, and Alan Hunter (1999), Quick Response: Managing the Supply Chain to Meet Consumer Demand, Chichester: John Wiley and Sons Ltd.

Mason-Jones, Rachel, James B. Naylor, and Denis R. Towill (2000), "Lean, Agile, or Leagile? Matching Your Supply Chain to the Marketplace," International Journal of Production Research, Vol. 30, No. 17, pp. 4061-4070.

Mason-Jones, Rachel and Denis Towill (1997), "Information Enrichment: Designing the Supply Chain for Competitive Advantage," Supply Chain Management, Vol. 2, No. 4, pp.137-148.

Mason-Jones, Rachel and Denis Towill (1999), "Using the Information De-coupling Point to Improve Supply Chain Performance," International Journal of Logistics Management, Vol. 19, No. 2, pp. 13-36.

McHugh, Patrick, Georgio Merli, and William Wheeler (1995), Beyond Business Process Re-Engineering, Chichester: John Wiley and Sons. 
Nagel, Roger and Richard Dove (1991), $2 I^{\text {st }}$ Century Manufacturing Enterprise Strategy, Leigh University: Iacocca Institute.

Naylor, J. Ben, Mohammed Naim, and Danny Berry (1999), "Leagility: Interfacing the Lean and Agile Manufacturing Paradigm in the Total Supply Chain," International Journal of Production Economics, Vol. 62, No.1/2, pp. 107-118.

Ohno, Taichi (1988), Toyota Production System: Beyond Large Scale Production, Cambridge, MA: Productivity Press.

Pagh, Janus and Martha Cooper (1998), "Supply Chain Postponement and Speculation Strategy: How to Choose the Right Strategy," Journal of Business Logistics, Vol. 19, No. 2, pp. 13-33.

Parnaby, John (1994), "Business Process Systems Engineering," International Journal of Technical Management, Vol. 10, pp. 497-507.

Porter, Michael (1980), Competitive Strategy, New York: The Free Press.

Sako, Mari (1992), Prices, Quality and Trust: Inter-Firm Relations in Britain and Japan, Cambridge: Cambridge University Press.

Schary, Philip and Toge Skjøtt-Larsen (1996), Managing the Global Supply Chain, Copenhagen: Handeklshǿjskoleus Forlag.

Shewchuck, Philip (1998), “Agile Manufacturing: One Size Does Not Fit All," in Process Integration Conference on Manufacturing Value Chains, Troon, pp. 143-150.

Siekman, Philip (2000), "New Victories in the Supply-Chain Revolution," Fortune, October 30.

Schonberger, Richard (1996), World Class Manufacturing: The Next Decade, New York: Free Press.

Stratton, Roy and Roger Warburton (2001), "Systematic Innovation and the Strategic Integration of Agile and Lean Supply, Theory and Practice," in Proceedings 16th ICPR, Prague, Paper No. A8.6.

Womack, James and Dan Jones (1996), Lean Thinking, New York: Simon and Schuster. 


\section{ABOUT THE AUTHORS}

James Aitken ( $\mathrm{Ph} . \mathrm{D}$. Cranfield University) spent the first 12 years of his industrial/commercial experience involved in all aspects of the supply chain ranging from the installation of a manufacturing postponement facility to the establishment of a pan-European transport and warehousing network. In 2000 he opened a new agile manufacturing facility to specialize in bespoke products. Dr. Aitken now operates as an independent consultant specializing in lean and agile manufacturing supply chains.

Paul Childerhouse (Ph.D. Cardiff University) is a senior lecturer at the University of Waikato, New Zealand. His research interests include enabling supply chain change and supply chain classification. He has first-hand industrial experience of the automotive, aerospace, dairy, construction, and retail sectors.

Martin Christopher (Ph.D. Cranfield University) is Professor of Marketing and Logistics at Cranfield School of Management. His work in the field of logistics and supply chain management has gained international recognition. He has published widely and his recent books include Logistics and Supply Chain Management and Marketing Logistics. Dr. Christopher is also co-editor of the International Journal of Logistics Management and is a regular contributor to supply chain management conferences and workshops around the world.

Denis Towill (D.Sc. University of Birmingham) is a University of Wales Research Professor and is presently Co-Director of the Logistics Systems Dynamics Group at Cardiff University. In 2000, he was awarded the Lord Hirst Prize by the Council of the Institution of Electrical Engineers. In 1988, he was elected a Fellow of the Royal Academy of Engineering in recognition of his major contributions to the theory of business systems engineering. His present major interest is researching the Seamless Supply Chain in order to provide proven methodologies for analysis, design, and implementation. 